\title{
Influence of mineral additions on the microstructure of concrete in chloride environment
}

\author{
Walid.Fouad Edris a,b, Safwat.Abdelkader ${ }^{\mathrm{b}}$, Encarnacion.Reyes Pozo ${ }^{\mathrm{c}}$, Amparo.Moragues Terrades $^{\mathrm{c}}$ \\ ${ }^{a}$ Department of Civil Engineering, Hijjawi Faculty for Engineering Technology, Yarmouk University. P.O. Box 566, \\ Irbid 21163, Jordan \\ ${ }^{b}$ Giza High Institute Of Engineering \& Technology, Awel Misr Assiut El Zeraay Rd., El Monib - Giza - Egypt, \\ ${ }^{c}$ Universidad Politécnica de Madrid, E.T.S.I. de Caminos, Canales y puertos, Madrid,8040, Spain.
}

\begin{abstract}
The use of blended cements incorporating materials such as natural pozzolans, blast furnace slag, fly ash or silica fume have an important role in the long-term durability of concrete exposed to marine environments. In this work we have designed an experimental campaign with four different dosages of concrete to study the influence of the principal additions used in marine environments. The concretes were prepared with the water-cementitious material ratio of 0.45 and tested at ages of 7, 28 and 91 days. The effect of material composition [Sulfate Resistant Portland Cement (SRPC), Blast Furnace Slag Portland Cement (BFSPC), Silica Fume (SF) and Fly Ash (FA) with four different mix designs] was performed by means of differential thermal analysis (DTA), mercury intrusion porosimetry (MIP), gas permeability, chloride diffusion and mechanical properties of concrete. In order to simulate the aggressiveness of the marine environment the concretes were immersed in a sodium chloride solution with a concentration of 1 molar during different times of 182, 365 and 546 days. The experimental procedure presented gives reliable information to evaluate the homogeneity of different concretes in terms of air permeability. According to the results obtained, the SRPC and SRPC+FA samples suffered the highest rise in permeability, porosity and chloride diffusion, and the greatest loss in compressive strength. In addition, the SRPC+SF and BFSPC produced paste with lowest permeability, porosity and chloride diffusion, and higher compressive strength than the original concrete SRPC
\end{abstract}

Key words: Permeability, DTA/TG, MIP, Chloride diffusion

\section{Introduction}

The structures exposed to marine environment are damaged by the chloride induced corrosión of steel bars in concrete. The permeable porosity affects the transport properties and durability of concrete. It is connected to many deterioration processes driven by transport properties of concrete. The porous medium of concrete permits the transport of chloride, oxygen, carbon dioxide and magnesium salts, which are known to cause corrosion in reinforcing bars $[1,2]$. The speed of degradation depends on the type of cements and water-to-cement ratio.

The literatures [3-6] recommend using cement with a low concentration of aluminates (sulfate resistant cement) or mineral additions mainly cement with fly ash and silica fume to improve the impermeability. Silica fume and fly ash are good pozzolanic materials for use in concrete, and many researchers have established their effects on concretes physical properties and pore structure. Huseyin et al. [7] investigated ordinary Portland cement (PC) and blast furnace slag blended cement

*Corresponding author: Address: Department of Civil Engineering, Hijjawi Faculty for Engineering Technology, Yarmouk University. P.O. Box 566, Irbid 21163, Jordan 
(SC) with respect to their mechanical properties and chloride diffusion coefficients, finding that SC cement can improve mechanical properties and decrease the chloride coefficient. Shannag and Shaia [6] studied ordinary Portland cement, Portland pozzolana cement and silica fume with respect to compressive strength and sulfate attack using an ultrasonic pulse velocity test. Based on their results, they concluded that the mix containing silica fume and natural pozzolana provided the maximum protection against sulfate attack. Roy [8] studied Portland cement, silica fume and fly ash. Based on the results obtained, they concluded that the chemical resistance of silica fume, metakawlin and fly ash series decreased as the replacement level increased, and chemical resistance increased with a change in the $\mathrm{W} / \mathrm{C}$ ratio from 0.36 to 0.4 . Using pozzolanic admixtures increased the sulfate resistance of blended cements in most cases. The use of fly ash and silica fume may have a positive effect on the sulfate resistance of blended cements [9-11]. However, the pore structure changes and bound water content due to differences in the properties of silica fume, slag cement and fly ash fineness are not well established. It has been recognized that the use of pozzolanic materials such as silica fume (SF) and fly ash (FA) is necessary for producing high performance concrete [12]. These materials, when used as mineral admixtures in concrete, can improve either or both the strength and durability properties of the concrete.

The investigation was performed by means of differential thermal analysis, mercury intrusion porosimetry, gas permeability, chloride diffusion and investigation of the mechanical properties of concrete. The relationships between the mechanical properties, permeability, pore median radius and bound water content of concrete are discussed and evaluated.

\section{Materials and Method}

In this study, the behavior of two types of sulfate resistant cement, namely Type I $42.5 \mathrm{R} / \mathrm{SR}$ sulfate resistance Portland cement (UNE-80303-1: 2001) [13] and type III /B 42.5 L/SR blastfurnace slag Portland cement (UNE-80303-1: 2001) [13], was evaluated. The two types were used in the design of four different concrete mixes, one for each cement type and two more using Type I plus two different additions, silica fume and fly ash, as cement replacements. In this case, two replacements, by the weight of cement, was investigated: $10 \%$ in the case of silica fume and $20 \%$ for the fly ash, within the limits allowed by current Spanish standards allow [14]. Table (1) summarizes the chemical compositions and physical properties of the cements, silica fume and fly ash used.

The fine aggregate used was a natural siliceous sand with a 2.8 fineness modulus. The coarse aggregate was crushed limestone with a maximum size of $20 \mathrm{~mm}$ and a 6.88 fineness modulus. In order to achieve proper workability, a super plasticizer (known commercially as Sika viscocrete 3425) was used as a high range water reducing agent [15].

Table 1. Chemical composition and physical properties of cementitious materials 


\begin{tabular}{|c|c|c|c|c|}
\hline Parameters (\%) & I $42.5 \mathrm{R} / \mathrm{SR}$ & III /B 42.5 L/SR & Silica fume & Fly ash \\
\hline $\mathrm{SiO2}$ & 21.58 & 26.70 & 85.0 & 40.66 \\
\hline Al2O3 & 3.48 & 7.40 & --- & 30.02 \\
\hline $\mathrm{Fe} 2 \mathrm{O3}$ & 4.78 & 1.80 & --- & 19.93 \\
\hline $\mathrm{CaO}$ & 67.64 & 50.20 & 1.0 & 8.09 \\
\hline MgO & 1.00 & 6.80 & --- & 1.70 \\
\hline $\mathrm{Na} 2 \mathrm{O}$ & --- & 0.23 & 1.5 & 0.22 \\
\hline K2O & --- & 0.78 & --- & 1.13 \\
\hline SO3 & 3.3 & 3.03 & 2.0 & 0.85 \\
\hline Cl- & 0.01 & 0.03 & 0.1 & 0 \\
\hline Loss to fire & --- & 1.50 & --- & 1.14 \\
\hline $\begin{array}{l}\text { Loss due to } \\
\text { calcinations }\end{array}$ & 3.16 & --- & 4.0 & --- \\
\hline Insoluble residue & 1.25 & 1.48 & --- & --- \\
\hline
\end{tabular}

\section{1. Mixture Proportions}

Four concrete mixtures were used, including sulfate resistance Portland cement (SRPC), blast furnace slag Portland cement (BFSPC), silica fume (SRPC + SF) and fly ash (SRPC + FA) concrete mixtures. The proportioning was done according to the EHE [14] recommendations. Table (2) shows the compositions of the mixtures.

Table 2. Details of concrete mixtures

\begin{tabular}{lllll}
\hline Parameters & SRPC & SRPC+SF & SRPC+FA & BFSPC \\
\hline Cement & 380 & 304 & 357 & 380 \\
Silica fume & 0 & 38 & 0 & 0 \\
Fly ash & 0 & 0 & 76 & 0 \\
Water & 171 & 154 & 194 & 171 \\
Coarse aggregate & 787 & 800 & 770 & 787 \\
Fine aggregate & 1022 & 1067 & 966 & 1022 \\
SP $(\%)$ & 0.97 & 1.8 & 0.7 & 1.3 \\
\hline
\end{tabular}

The concrete was designed using the method of La Peña [16]. In the mixtures in which silica fume $(\mathrm{SRPC}+\mathrm{SF})$ and fly ash $(\mathrm{SRPC}+\mathrm{FA})$ were added to concrete, we followed the recommendations of the EHE [14], replacing the cement contents (C) with cementitious material $(\mathrm{C}+\mathrm{KF})$, where $\mathrm{F}$ is the content of the addition and $\mathrm{K}$ is the coefficient of effectiveness. For the efficiency ratio used, $\mathrm{K}=2$ for the silica fume and $\mathrm{K}=0.3$ for the fly ash. The concrete mixtures were prepared with a water-to-cementitious-materials ratio $(\mathrm{w} / \mathrm{cm})$ of 0.45 .

\subsection{Test specimens and procedures}

Standard UNE-EN-12390-2 [17] procedures were used for casting, curing, and testing the concrete specimens.

The mechanical characterization of the concrete was carried out using measurements of compression strength, splitting tensile strength and elastic modulus. For compression strength, the specimens were tested in accordance with UNE-EN-12390-3 standards [18] at the ages of 7 and 28 days; the results were calculated as the mean of the three measurements. Split-cylinder tests were 
carried out according to UNE-EN-12390-6 [19] at the age of 28 days on three specimens for each mixture. Finally, the elastic modulus was measured following the procedures of UNE-83316 [20] at the age of 28 days.

Gas Permeability was evaluated for the four mixtures. The transport of oxygen was studied by means of a gas permeability measuring instrument according the specifications of RILEM TC 116PCD [21]; in this case, one specimen was submerged in the chloride solution until reaching the ages of 182, 364 and 546 days.

In order to measure the porosity of the concrete, a mercury intrusion porosimetry test was carried out in accordance with ASTM D 4404-84 [22].

Finally, differential thermal analysis and thermogravimetry tests were carried out with the aim of studying the hydrated compounds

\section{Results}

The 7 and 28 day compressive strengths were measured for all mixtures, and the measured values are presented in table 3. In the case of SRPC $+\mathrm{SF}$ concrete, high compressive strengths were achieved at the age of 7 days, which confirms the well-known fact that silica fume improves compression resistance at an early age [17]. On the other hand, the SRPC + FA mixture achieved lower strength than the rest of concrete mixtures. The effective surface area and pozzolanicity of the mineral admixture influenced the hydration rate. The lower strength observed for the fly ash concrete mixture may be attributed mainly to its low reactivity. It is important to note that the period needed for SRPC + FA concrete to develop maximum compressive strength is much longer than in the other concretes, and 28 days is not sufficient.

The mean splitting tensile strength values are shown in Table 3. Each data point is the average for three cylindrical specimens. As shown in Table 3, tensile strength was higher in the SRPC and BFSPC concrete mixtures. The splitting tensile strength results indicate that the addition of silica fume and fly ash to concrete does not seem to improve tensile behavior as it does for other properties.

Table 3. Mechanical Properties of Concrete

\begin{tabular}{lllll}
\hline \multirow{2}{*}{ Mixtures } & \multicolumn{2}{l}{ Compressive strength $(\mathrm{MPa})$} & $\begin{array}{l}\text { Splitting tensile } \\
\text { strength }(\mathrm{MPa})\end{array}$ & $\begin{array}{l}\text { Modulus of } \\
\text { elasticity }(\mathrm{GPa})\end{array}$ \\
\cline { 2 - 5 } & 7 days & 28 days & 28 days & 28 days \\
\hline SRPC & 45 & 49 & 5 & 36 \\
\hline SRPC + SF & 51 & 57 & 4.5 & 38 \\
\hline SRPC + FA & 36 & 47 & 4 & 31 \\
\hline BFSPC & 43 & 53 & 5 & 38 \\
\hline
\end{tabular}

The average elastic modulus values at 28 days are the last measurement displayed in Table 3. SRPC, SRPC+FA concretes have a lower elastic modulus. SRPC+SF and BFSPC concretes present the same value. 


\subsection{Thermogravimetry}

As a result of the DTA test, one curve was obtained on which three zones could be observed. The first curve, delimited by 100 and $300^{\circ} \mathrm{C}$, was attributed to the dehydration of C-S-H and ettringite [23]. The temperature at which these compounds lose water depends on the available $\mathrm{CaO}: \mathrm{SiO} 2$ ratio in the hydrated cement matrix. The second zone covers the range between 290 and $350^{\circ} \mathrm{C}$, characterizing the decomposition of calcium aluminate silicate hydrate, calcium aluminate hydrate and calcium chloroaluminate [24]. Finally, the third curve, which ranges from 450 to $510^{\circ} \mathrm{C}$, was attributed to the dehydration of calcium hydroxide. An endotherm around $700^{\circ} \mathrm{C}$ indicates the decarbonation of calcium carbonate in the hydrated compound.

The results obtained for $\mathrm{Ca}(\mathrm{OH}) 2$ content with hydration time in all concrete mixtures are presented in Figure 1. As shown in Figure 1, the $\mathrm{Ca}(\mathrm{OH}) 2$ content is more extensive in the SRPC concrete at all hydration times compared to the slag, silica fume and fly ash concrete mixes. The lower content of $\mathrm{Ca}(\mathrm{OH}) 2$ in the slag and pozzolanic additions indicates its consumption in the pozzolanic reaction. In the SRPC+SF concrete, the results indicate the presence of more pozzolanic reaction of silica fume than in the rest of the concretes, which is consistent with the findings of other researchers [25]. The lower $\mathrm{Ca}(\mathrm{OH}) 2$ content at all hydration times in pozzolanic additions and slag cement has been reported previously based on TG/DTA analyses of cement pastes [23]. The results obtained are consistent with the high level of $\mathrm{SiO} 2$ of the cement I 42.5 R/SR and the greater speed of consumption of $\mathrm{Ca}(\mathrm{OH}) 2$ with silica in the form of $\mathrm{C} 3 \mathrm{~S}$.

Figure 2 shows the obtained variation in calcium hydrate content versus hydration time for all concrete mixtures. In all cases, calcium hydrate content tended to increase with time across all the measured ages. The calcium hydrate content at 182, 364 and 546 days was lower in the SRPC concrete than in the rest of mixtures. Higher values of calcium hydrates were found in SRPC+FA concrete because of its higher alumina and calcium oxide content.

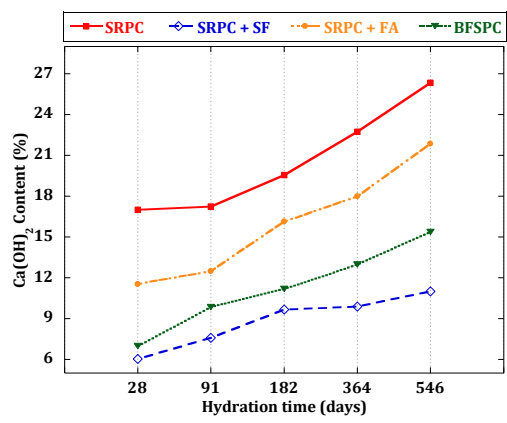

Figure 1: Variation in $\mathrm{Ca}(\mathrm{OH}) 2$ Content with Hydration Time

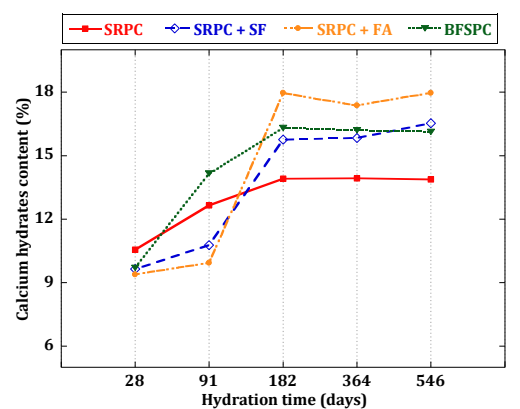

Figure 2: Variation in Calcium Hydrate Content with Hydration Time

When comparing Figures 1 and 2, the increase in $\mathrm{Ca}(\mathrm{OH}) 2$ in the SRPC + FA mixture is observed to be compatible with the increase in $\mathrm{C}-\mathrm{S}-\mathrm{H}$ due to hydration reaction kinetics. The results obtained are in accordance with the compression strength values. 


\subsection{Porosimetry by mercury intrusion}

Tests were carried out at 182, 364 and 546 days in order to observe changes in the porosimetry in relation to the effect of chloride ions on the evolution of the hydration reactions.

Figures 3 and 4 show the results of the pore size distribution for the four concretes exposed to aggressive solution of $\mathrm{NaCl}$ at 182, 364 and 546 days of exposure. They can see that the main peak (critical diameter) in the four concrete immersed in this solution is located between 17 and $32 \mathrm{~nm}$, interval corresponding to the range of mesopores $(10-50 \mathrm{~nm})$. The concretes BFSPC and $\mathrm{SRPC}+\mathrm{SF}$ are presented the lowest critical diameter in this environment, this parameter is between the values of 17 and $21 \mathrm{~nm}$ for SRPC+SF concrete and the diameter of 21 and $26 \mathrm{~nm}$ for BFSPC concrete. As can be seen in figures 3 and 4 both the pore size, as the total pore volume decreased significantly introduced with increasing hydration time is an indication of the decrease in total porosity.

A comparison of the results of the concretes studied shows that the BFSPC and SRPC+SF concretes had the lowest volume of intrusion along the length of exposure, due to the smaller size of pores. Similarly, the behavior of SRPC and SRPC+FA concretes is similar; in this case the change in the distribution of pores with time in concrete made with fly ash is lower in this medium for the lower content of calcium (Figure 3).

The BFSPC concrete shows the lowest total porosity, followed by SRPC+SF, and SRPC+FA, in that order. The beneficial effect of using slag and silica fume is obvious (Figure 3).

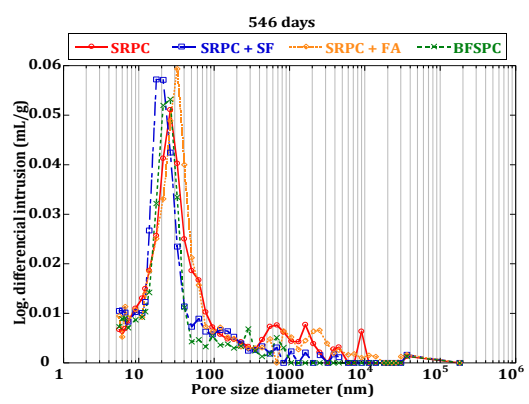

Figure 3. Pore size distribution at 546 days in chloride solution

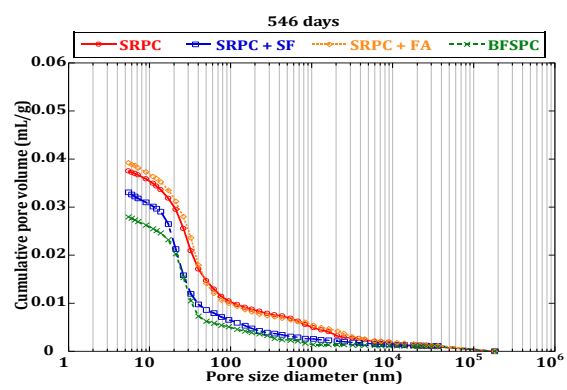

Figure 4. Total pores at 546 days in chloride solution

\subsection{Gas permeability}

The coefficients of gas permeability values at the ages of 182, 364 and 546 days for all concrete specimens are shown in Figure 5. These values were in the range of 0.95 x 10-18 $\mathrm{m} 2$ (at exposure time of 182 days) to $4.26 \times 10-18 \mathrm{~m} 2$ (at exposure time of 546 days) for concrete mixtures with mineral additions, the least permeable mixture. SRPC concrete represent the other extreme; the experimental results were in the range of $5.71 \times 10-18 \mathrm{~m} 2$ (at exposure time of 182 days) to $6.1 \mathrm{x}$ $10-18 \mathrm{~m} 2$ (at exposure time of 546 days). In all cases, the coefficient of gas permeability is higher with increasing the exposure time. This indicates mineral additions was modified the pore structure throughout the specimen. 


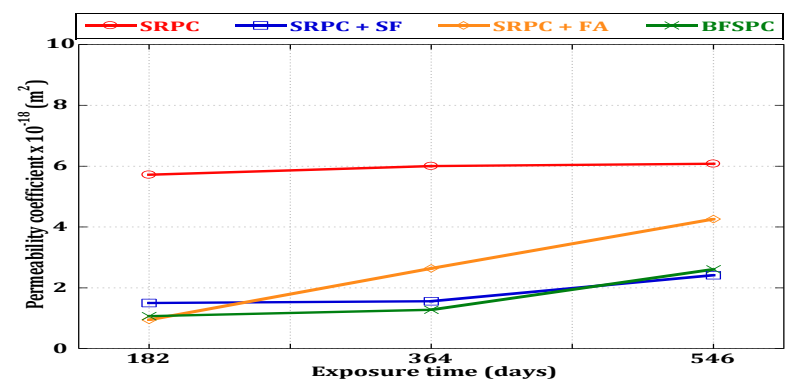

Figure 5. Coefficient of gas permeability in all types of concrete at different exposure time in $\mathrm{NaCl}$ solution

Based on this experiment, the permeability of the concretes with the addition of silica fume (SRPC+SF) and BFSPC is found to be much lower than that of the other two mixtures, as can be seen in Figure 5 in accordance with the porosimetry results. From the above results, it appears that the quality of the mortar matrix is the most important parameter in determining the permeability of concrete.

\subsection{Chloride ion penetration}

Figures 6-9 shows the chloride content profiles of all concrete at 182, 364 and 546 days exposure, where each value is the average of two measurements. The results showed that the silica fume and blast furnace slag concretes presented lower $\mathrm{Cl}$ than fly ash and control concrete at all exposure times and it was also confirmed by other researches $(12,26)$. The results indicated that the rate of chloride diffusion for the initial exposure time (from 182 to 364 days) in all concretes was a higher than that of the ultimate exposure time (from 364 to 546 days). The faster rate of chloride penetration was leading to the faster rate of corrosion.

Using of silica fume and blast furnace slag cement helps the concrete to resist the chloride penetration since the lower rate of chloride content was found as compare to the concrete without additions and the concrete with fly ash (Figures 6-9).

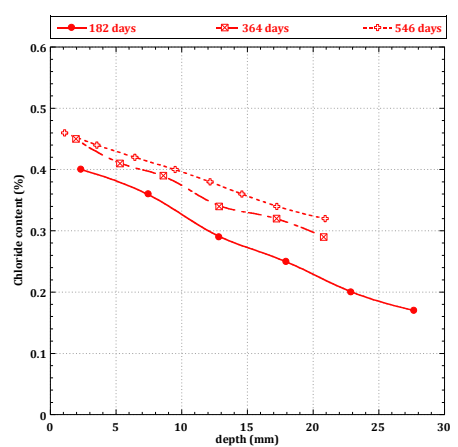

Figure 6. Chloride content profiles at different exposure period of concrete SRPC

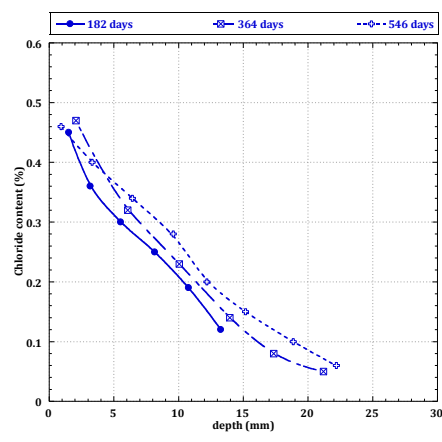

Figure 7. Chloride content profiles at different exposure period of concrete SRPC $+\mathrm{SF}$ 


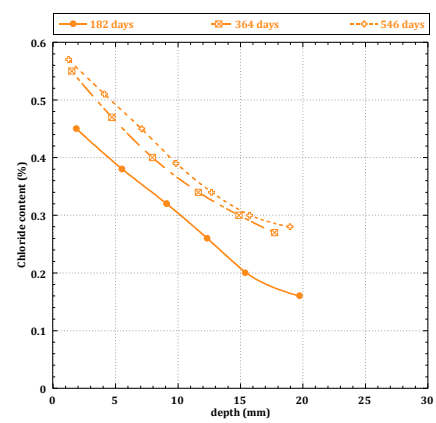

Figure 8. Chloride content profiles at different exposure period of concrete SRPC + FA

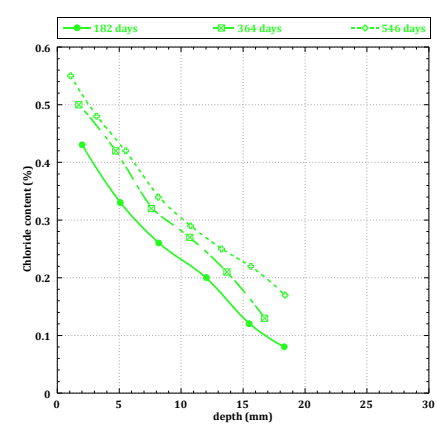

Figure 9. Chloride content profiles at different exposure period of concrete BFSPC

\section{Conclusions}

The four concrete mixtures studied can be divided into two pairs, according to their behavior. On the one hand, SRPC and SRPC+FA concretes show similar behavior, with lower strength and higher permeability, while SRPC+SF and BFSPC show higher strength and lower permeability. The addition of fly ash delayed the process by which the microstructure of pores of the sulfate resistance Portland cement developed, and this was used as a reference for the SRPC mixture. Permeability, which is intrinsically related to porosimetry, represents a potential risk of significant deterioration. Regarding silica fume and blast furnace slag addition in the SRPC+SF and BFSPC concrete mixtures, permeability coefficient was lower than in plain (SRPC) and fly ash (SRPC+FA) concrete mixtures at all exposure ages. The reduced permeability of these concretes is mainly attributed to both a dilution effect and the pozzolanic reaction. The harmful effect of the penetration of aggressive substances is reduced by the size of the pores in these concretes. The use of mineral additions improved significantly the resistance of concrete to penetration of chloride ion. During the exposure time the concretes SRPC+SF and BFSPC had the best evolution of resistance to chloride ion penetration, reducing clearly the chloride diffusion coefficients with age. The possibility of aluminous compound formation between chloride and the addition of slag, reduce the speed of the chloride in these concretes.

\section{Acknowledgements}

The project presented in this article is supported by Polytechnic University of Madrid and Yarmouk University of Jordan.

\section{References}

1. Mehta P. K. "Concrete in the marine environment." London: Taylor \& Francis; 2003

2. Safiuddin Md., Hearn N. "Comparison of ASTM saturation techniques for measuring the permeable porosity of concrete”, Cement and Concrete Research 2005; 35: 1008-1013.

3. Ganjian E., Pouya H. Effect of magnesium and sulfate ions on durability of silica fume blended mixes exposed to the seawater tidal zone. Cement and Concrete Researsh 2005; 35 :

1332-1343. 
4. Lee S. T. H., Swamy R.N. Sulfate attack and role of silica fume in resisting strength loss. Cement \& Concrete Composites 2005; 27: 65-76.

5. Sezer G., Ramyar K., Karasu B. A. B., Sezer A. Image analysis of sulfate attack on hardened cement past. Materials and Desig 2008; 29: 224-231.

6. Shannag M. J., Hussein A.S. Sulfate resistance of high-performance concrerte. Cement \& Concrete Composites 2003; 25: 363-369.

7. Huseyin Y., Halit Y., Serdar A. Effects of cement type, water/cement ratio and cement content on sea water resistance of concrete. Building and Environment 2007; 42: 1770-1776.

8. Roy D.M., Arjunan P., Silsbee M.R. Effect of silica fume, metakaolin, and low-calcium fly ash on chemical resistance of concrete. Cement and Concrete Research 2001; 31: 1809-1813.

9. Sideris K.K., Savva A.E., Papayianni J. Sulfate resistance and carbonation of plain and blended cements., Cement \& Concrete Composites 2006; 28: 47-56.

10. Al-Dulaijan S. U., Maslehuddin M., Al-Zahrani M. M., Sharif A. M., Shameem M. and Ibrahim M. Sulfate resistance of plain and blended cements exposed to varying concentrations of sodium sulfate, Cement and Concrete Composites 2003; 25: 429-437 .

11. Mitchell L. D, Margeson J. C. The effects of solvents on C-S-H as determined by thermal analysis. Journal of Thermal Analysis and Calorimetry 2006; 86: 591-594.

12. Poon C.S., Kou S.C., Lam L. "Compressive strength, chloride diffusivity and pore structure of high performance metakaolin and silica fume concrete." Construction and Building Materials; 2006; 20: 858-865.

13. UNE. 80303-1 Cements with additional characteristics. Part 1: Sulphate resisting cements; 2001.

14. EHE. Spanish Instruction of Structural Concrete; 2008.

15. ASTM C494 / C494M - 05 Standard Specification for Chemical Admixtures for Concrete; 2005.

16. Canovas MF., Concrete. 7th ed. Madrid (Spain): Colegio de Ingenieros de Caminos, Canales y Puertos; 2004 (in Spanish).

17. UNE-EN - 12390-2 Testing hardened concrete - Part 2: Making and curing specimens for strength tests; 2001.

18. UNE-EN - 12390-3 Testing hardened concrete - Part 3: Compressive strength of test specimens; 2003.

19. UNE-EN - 12390-6 Testing hardened concrete - Part 6: Tensile splitting strength of test specimens; 2001.

20. UNE - 83316 Concrete tests. determination of the modulus of elasticity in compression; 1996.

21. RILEM TC 116-PCD Tests for gas permeability of concrete - Preconditioning of concrete test specimens for the measurement of gas permeability and capillary absorption of water Measurement of the gas permeability of concrete by the RILEM - CEMBUREAU method Determination. RILEM Publications SARL 1999; 32: 174 - 179. 
22. ASTM D 4404-84 Test Method for Determination of the Pore Volume and Pore Volume Distribution of Soil and Rock by Mercury Intrusion Porosimetry; 1985.

23. Lea F.M. The Chemistry of Cement and Concrete. Fourth Edition. Edward Arnold; 1974.

24. Ubbriaco P., Calabrese D. Solidification and stabilization of cement paste containing fly ash from municipal waste. Thermochimica Acta 1998; 321: 143.

25. Bentz D. P., Stutzman P. E. Evolution of porosity and calcium hydroxide in laboratory concretes containing silica fume. Cement and Concrete Research 1994; 24: 1044-1050.

26. Bai J., Wild S., Sabir B.B., Chloride ingress and strength loss in concrete with different PCPFA-MK binder 